\title{
Are Biodegradable Osteosyntheses Still an Option for Midface Trauma? Longitudinal Evaluation of Three Different PLA-Based Materials
}

\author{
Andreas Kolk, ${ }^{1}$ Robert Köhnke, ${ }^{2,3}$ Christoph H. Saely, ${ }^{4}$ and Oliver Ploder ${ }^{3,5}$ \\ ${ }^{1}$ Department of Oral- and Craniomaxillofacial Surgery, Klinikum Rechts der Isar der Technischen Universität München, \\ Ismaninger Strasse 22, 81675 Munich, Germany \\ ${ }^{2}$ Department for Oral- and Maxillofacial Surgery, University Medical Center Hamburg-Eppendorf, Martinistrasse 52, \\ 20246 Hamburg, Germany \\ ${ }^{3}$ Department of Oral- and Maxillofacial Surgery, Academic Teaching Hospital Feldkirch, Carinagasse 47, 6800 Feldkirch, Austria \\ ${ }^{4}$ Department of Medicine and Cardiology, VIVIT Research, Academic Teaching Hospital, Carinagasse 47, 6800 Feldkirch, Austria \\ ${ }^{5}$ Department of Craniomaxillofacial and Oral Surgery, Medical University Vienna, Vienna General Hospital, \\ Waehringer Guertel 18-20, 1090 Vienna, Austria
}

Correspondence should be addressed to Andreas Kolk; kolk@mkg.med.tum.de

Received 26 March 2015; Accepted 16 June 2015

Academic Editor: Joo L. Ong

Copyright (c) 2015 Andreas Kolk et al. This is an open access article distributed under the Creative Commons Attribution License, which permits unrestricted use, distribution, and reproduction in any medium, provided the original work is properly cited.

\begin{abstract}
The aim was to evaluate three different biodegradable polylactic acid- (PLA-) based osteosynthesis materials (OM). These OM (BioSorb, LactoSorb, and Delta) were used in 64 patients of whom $55(85.9 \%)$ had fractures of the zygoma, five (7.8\%) in the LeFort II level, two of the frontal bone (3.1\%), and two of the maxillary sinus wall (3.1\%). In addition to routine follow-up (FU) at 3, 6, and 12 months (m) (T1, T2, and T3) all patients were finally evaluated at a mean FU after $14.1 \mathrm{~m}$ for minor (e.g., nerve disturbances, swelling, and pain) and major (e.g., infections and occlusal disturbances) complications. Out of all 64 patients 38 presented with complications; of these 28 were minor $(43.8 \%)$ and 10 major $(15.6 \%)$ resulting in an overall rate of $59.4 \%$. Differences in minor complications regarding sensibility disturbance at $\mathrm{T} 1$ and $\mathrm{T} 3$ were statistically significant $(P=0.04)$. Differences between the OM were not statistically significant. Apart from sufficient mechanical stability for clinical use of all tested OM complications mostly involved pain and swelling probably mainly related to the initial bulk reaction attributable to the drop of $\mathrm{pH}$ value during the degradation process. This paper includes a review of the current aspects of biodegradable OM.
\end{abstract}

\section{Introduction}

In maxillofacial trauma, osteosynthesis materials $(\mathrm{OM})$ manufactured from titanium have been routinely used for many years $[1,2]$. Such bone plates are biocompatible and provide adequate stability. Several potential problems with these systems can occur including palpability, temperature sensitivity, infection, interference with radiographic imaging $[3,4]$ and radiation therapy, and the necessity of removal especially in the young growing face after 3-6 months $(\mathrm{m})$ [5]. Additionally, scar tissue covering these plates and locoregional lymph nodes can contain titanium particles [6]. In a recent publication, titanium plates have even been seen as a risk factor for the development of the bisphosphonate-related osteonecrosis of the jaw [7]. In order to avoid these problems, biodegradable synthetic semicrystalline polymers that are mainly polylactic acid- (PLA-) based have been developed for use as OM in maxillofacial trauma $[8,9]$. Since their first descriptions in the 1970s and mainly within the last 20 years, biodegradable OM have been investigated and shown to achieve adequate strength, rigidity, and biocompatibility [10-14]. Initially, synthetic polymers of lactic (PLA) and glycolic (PGA) acid were considered to be biocompatible and rigid [15], with PLA also serving as a device for controlled drug delivery in addition to its use as an $\mathrm{OM}[16,17]$. Because of various problems with OM based only on PGA, 
and because of the early loss of stability attributable to fast degradation [18], further developments have concentrated more on the high-molecular-weight biodegradable polymer PLA, a combination of two different stereoisomeric forms such as poly-L-lactide (PLLA) and poly-D-lactide (PDLA), or a combination of PLA and PGA. The last-mentioned form is characterized by an inferior degradation rate attributable to lower crystallinity and minor resistance against hydrolysis. To combine properties, copolymers of PLA are joined in different ratios of PLLA and PDLA.

Thus, many different materials with diverse compositions of PLA for various applications in the field of oral and maxillofacial surgery are available on the market and are used in the treatment of fractures of the frontal bone and midface $[19,20]$. Although many of these materials are widespread, no evidence has been presented for their indication and localization, or whether they can serve as an alternative to titanium-based OM. Most problems with biodegradable OM are related to the duration of the degradation process with a consecutive change of the local tissue environment caused by foreign body reaction and tissue shrinking mainly within weeks, but also up to many months after implantation.

The vast majority of clinical studies have compared the outcome of the use of biodegradable materials with titanium in the treatment of midface fractures [21-24]. The results of the latter studies have shown no differences between biodegradable and titanium fixation regarding short-term outcome. Little long-term data are available concerning comparisons of various biodegradable materials in clinical applications $[21,25]$. Therefore, the aim of this study has been to evaluate the use of three different biodegradable OM in the treatment of midface trauma and to analyze their long-term clinical outcome.

\section{Patients and Methods}

Over a period of 45 months, 64 patients (50 men and 14 women, mean age $( \pm S D) 30.2 \pm 15.4$ years, ranging from 6 to 80 years) with fractures of the midfacial skeleton were enrolled in the study and, after randomization, were treated at the University Hospital of Cranio-Maxillofacial and Oral Surgery of the Medical University Vienna with three different biodegradable $\mathrm{OM}$ as an alternative to the classic titanium OM: BioSorb (copolymer with PLLA/PDLA (ratio $70: 30$ ), Bionx Implants Linvatec Corp., Largo, FL, USA) (BS), LactoSorb (amorphic copolymer with PLLA/PGA (ratio 82:18), Walter Lorenz Surgical, Inc., Jacksonville, FL, USA) (LS), and Delta (terpolymer with PLLA/PDLA/PGA (ratio 85:5:10), Stryker Leibinger Micro Corp., Freiburg, Germany) (DS).

In contrast to the two other OM (LS/DS), BS plates on the basis of a self-reinforced poly (L-/DL-) $(70: 30)$ lactic acid copolymer can be adapted to the bony contour (Figure 1) at room temperature without any heating. To obtain a preferably homogeneous collective, patients were selectively filtered for this study. Subjects with previous surgery or systemic diseases, such as diabetes or osteoporosis, were excluded. After choosing biodegradable $\mathrm{OM}$ as an alternative to titanium, all patients gave their written informed consent for the surgical procedure and research purposes at the time
TABLE 1: Categories of potential complications.

\begin{tabular}{|c|c|}
\hline Minor complications & Major complications \\
\hline Swelling* & Infection \\
\hline Redness* & Malocclusion \\
\hline Pain* & Revision surgery \\
\hline Sensitivity disturbance & $\begin{array}{c}\text { Ectropion } \\
\text { Hypertrophic scar }\end{array}$ \\
\hline
\end{tabular}

${ }^{*}$ Recorded if still observed at the final clinical investigation date (mean final FU after $14.1 \mathrm{~m}$ ).

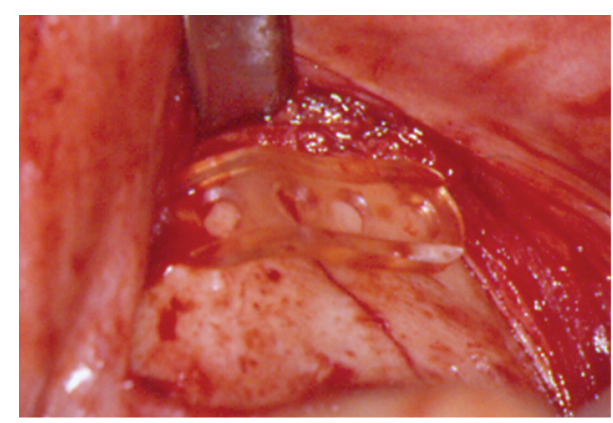

FIGURE 1: Intraoperative view. Adaption of biodegradable OM in the zygoma region.

of initial presentation. The local hospital ethic committee approved the study. Three, six, and twelve $m$ after trauma (time points T1, T2, and T3), patients took part in routine follow-up (FU) with clinical and radiological examination (conventional X-rays or CT scans) by one investigator using a standardized FU protocol. Preoperative data were taken from the charts of each patient. All findings (temporary and permanent symptoms) that occurred during any part of the observation period were recorded and categorized as minor (e.g., swelling, pain, or nerve disturbance) or major (infection, occlusal disturbance, need of revision surgery, or hypertrophic scar) complications (Table 1). Parameters such as swelling and redness were recorded with yes/no answers. Pain was documented on a visual analog scale (VAS $>0$ ) from 0 to 10 . All the last-mentioned parameters were classified as minor complications if they were still observed at investigation date T1-T3. Potential dysfunctions (an-, hyp-, and paraesthesia) of the trigeminal nerve branches were tested on both sides at the forehead, cheek, nose, and lip area by using the touch-detection-threshold at T1-T3. Further postoperative findings such as infections were recorded. Maximum mouth opening and occlusal conditions (centric occlusion, lateral excursions, and occlusal disturbance) were analyzed in cases of occlusal involvement of the central midface (Table 1$)$. At the end of the study after a mean $( \pm S D)$ of $14.1 \pm 0.8 \mathrm{~m}$ a final clinical examination took place in addition to the previous FU at T3.

Descriptive statistics for quantitative variables are given as means \pm standard deviation and, where appropriate, as medians and ranges. All data were analyzed with the "Statistical Package for the Social Sciences" (SPSS for windows, release 14.0.0 2011; SPSS Inc.). All $P$ values given are 
TABLE 2: Distribution of fracture localization and applied OM $(N=$ 64).

\begin{tabular}{lcccc}
\hline Localization & Number & \multicolumn{3}{c}{ Material } \\
& & BS & LS & DS \\
\hline Frontal bone & 2 & $2(1.5)$ & & \\
Midface & & & & \\
$\quad$ Le Fort II & 5 & $5(2.0)$ & & \\
$\quad$ Zygoma & 55 & $27(1.5)$ & $12(1.5)$ & $16(1.7)$ \\
$\quad$ Max. sinus wall & 2 & $2(1.5)$ & & \\
\hline Total & 64 & 36 & 12 & 16 \\
\hline
\end{tabular}

OM with plate thickness behind the number $(\mathrm{mm})$; BS: Biosorb; LS: LactoSorb; DS: Delta.

unadjusted, two-sided, and subject to a significance level of $P<0.05$.

\section{Results}

In 64 patients, the fractures were treated with three different biodegradable OM (BS, LS, and DS); 55 patients $(85.9 \%)$ had zygoma fractures, five patients $(7.8 \%)$ had fractures in the LeFort II level, two of the frontal bone $(3.1 \%)$, and two of the maxillary sinus wall (3.1\%) (Table 2). Thirty-six patients $(56.2 \%)$ were treated with BS, 12 patients $(18.8 \%)$ were treated with LS, and in 16 cases (25\%) DS was used. Fracture localization, the number of cases in each area, and the OM used are shown in detail in Table 2. The mean time interval $( \pm \mathrm{SD})$ between trauma and operation was $3.9 \pm 4.8$ days. Patients were divided into two groups regarding the time duration to fracture reduction: one group was operated up to day 4 after injury and the other between 5 and 9 days after trauma. The difference between the two groups was not statistically significant. The mean final clinical FU $( \pm$ SD) was after $14.1 \pm 0.8 \mathrm{~m}$ (ranging from 12.4 to $22 \mathrm{~m}$ ). All fractures showed stable healing without any signs of redislocation until T1. None of the patients required any revision surgery or other additional procedures.

Out of the total collective $(N=64) 38$ patients presented with problems, of these $28(43.8 \%)$ had minor and $10(15.6 \%)$ major complications resulting in an overall complication rate of $59.4 \%$. Whereas differences regarding sensory disturbance between $\mathrm{T} 1$ and T3 were statistically significant $(P=0.04)$, the variances in the outcome between the materials were statistically not significant (Tables 3 and 4). Twelve months postoperatively (T3), 37 patients (57.8\%) experienced pain in the plate region (VAS $>0$ ): out of the latter subgroup, 28 patients belonged to group BS $(77.8 \%)$, two to group LS (16.7\%), and seven to group DS (43.8\%). The difference between the materials was not statistically significant. At the final clinical investigation date (mean $14.1 \mathrm{~m}$ postoperatively), pain (VAS $>0$, mean $\pm \mathrm{SD}, 3.05 \pm 1.31$ ) was still present and was considered as quality-of-life-limiting complaints in 19 patients of group BS, one of group LS, and 6 of subgroup DS. Differences between the materials were statistically marginally significant $(P=0.05)$.

In 18 patients treated with BS (50.0\%), in three patients of group LS (25.0\%), and in five patients with DS (31.3\%), swelling was still evident at the final clinical evaluation time point (after mean $14.1 \mathrm{~m}$ ). The differences between the materials were statistically not significant. The presence of nerve disturbance and its different degrees of severity or quality, the fracture localization, and the applied OM subgroup are displayed in Tables 3 and 4.

\section{Discussion}

The use of titanium plates and screws for the treatment of facial fractures is well documented and accepted as the treatment of choice $[1,2]$. In order to avoid implant-related problems with these materials, for example, palpable and prominent plates or thermal sensitivity followed by a second operation for removal, biodegradable OM were invented for the treatment of facial fractures more than 40 years ago $[10,12,26-30]$. Additionally, these materials are used for craniofacial and reconstructive facial surgery [23, 30, 31]. Nevertheless, only a few studies have compared outcome with regard to the localization and different material compositions of the OM $[22,24,25,32]$. The complication rate in these investigations varies between $0.0 \%$ and $22.8 \%$ [22, 24, 31, 32]. Eppley et al. have reported their experience and success with L-/DL-lactide (70/30) for the fixation of maxillofacial trauma, including fractures of the central midface, zygoma, and orbital rim and floor [23]; they observed no implant-related complications (e.g., infection, erythema, fracture instability, or relapse) up to one year after fixation. Enislidis et al. have recorded $22.8 \%$ of minor complications by using BioSorb (BS) for the fixation of zygoma fractures [24]. In contrast to the current literature and an analysis of the latter, we have obtained a much higher complication rate of $59.4 \%$, independent of the material. This can be explained by the long-term FU and the extensive listing of various clinical symptoms, including swelling, being categorized as major or minor complications. Furthermore, the evaluation of swelling and pain have been categorized with yes or no answers and assigned to minor complications, for example, each patient presenting with swelling (yes or no answers) or pain (VAS $>0$ equals pain). The majority of minor complications are related to pain and swelling. At T3 even 37/64 patients (57.8\%) and even at the final FU 26 of 64 patients (40.6\%) still exhibited pain and swelling in the plate region. The high number of these symptoms can probably be explained by implant-related foreign body reaction (Figure 2) caused by the material-associated degradation process and the thickness of the plates (Figure 1) in general with local tissue trauma. Bioresorbable polymers are mainly high-molecularweight aliphatic polyesters with repeating units of $\alpha$-hydroxy acid (HO- CHR-COOH) derivatives manufactured by ringopening polymerization [33]. The absorption of these polymers begins with depolymerization through the acid hydrolysis of their ester bonds. The local $\mathrm{pH}$ value drops followed by a change in osmotic pressure. Toxic responses result [34] in concomitant damage of macrophages and fibroblasts [35], and osteoblasts are affected [36]. The resulting chronic inflammatory response by the body leads to acid hydrolytic degradation [37-39]. The material is probably metabolized by macrophages via the citric acid cycle and converted into $\mathrm{CO}_{2}$ 
TABLE 3: Fracture localization and distribution and quality of nerve disturbance $(N=64)$.

\begin{tabular}{|c|c|c|c|c|c|c|c|}
\hline FU & Localization & Norm (\%) & Hyp (\%) & Par (\%) & An (\%) & MD (\%) & $P$ \\
\hline $\mathrm{T} 1$ & Upper jaw & $11(17.2)$ & $43(67.2)$ & 7 (10.9) & $3(4.7)$ & 0 & \\
\hline $\mathrm{T} 2$ & Upper jaw & 35 (54.7) & $26(40.6)$ & $2(3.1)$ & $1(1.6)$ & 0 & \\
\hline T3 & Upper jaw & $50(78.1)$ & $8(12.5)$ & $4(6.3)$ & $1(1.6)$ & $1(1.6)$ & $0.045^{*}$ \\
\hline
\end{tabular}

FU: Follow-up time point in months (m), (T1 = 3 m, T2 = 6 m, T3 = $12 \mathrm{~m})$; Norm: normal; Hyp: hypaesthesia; Par: paraesthsia; An: anaesthesia; MD: missing data. Apart from T1 versus T3, no statistical significance was seen between the FU time points, level of significance * $(P<0.05)$.

TABLE 4: Nerve disturbance depending on FU and OM $(N=64)$.

\begin{tabular}{|c|c|c|c|c|c|c|c|}
\hline $\mathrm{FU}$ & $\mathrm{OM}$ & Norm & Hyp & Par & An & $\mathrm{MD}$ & $P$ \\
\hline \multirow{3}{*}{$\mathrm{T} 1$} & BS & $5(13.9 \%)$ & $25(69.4 \%)$ & $3(8.3 \%)$ & $3(8.3 \%)$ & 0 & - \\
\hline & LS & $2(16.7 \%)$ & $10(83.3 \%)$ & 0 & 0 & 0 & - \\
\hline & DS & $4(25.0 \%)$ & $8(50.0 \%)$ & $4(25.0 \%)$ & 0 & 0 & - \\
\hline \multirow{3}{*}{$\mathrm{T} 2$} & BS & $14(38.9 \%)$ & $14(38.9 \%)$ & $2(5.6 \%)$ & $1(2.8 \%)$ & $5(13.9 \%)$ & - \\
\hline & LS & $9(75.0 \%)$ & $3(25.0 \%)$ & 0 & 0 & 0 & - \\
\hline & DS & $11(68.8 \%)$ & $3(18.8 \%)$ & $2(12.5 \%)$ & 0 & 0 & - \\
\hline \multirow{3}{*}{ T3 } & BS & $23(63.9 \%)$ & $5(13.9 \%)$ & $2(5.6 \%)$ & $1(2.8 \%)$ & $5(13.9 \%)$ & - \\
\hline & LS & $10(83.3 \%)$ & $2(16.7 \%)$ & 0 & 0 & 0 & - \\
\hline & DS & $12(75.0 \%)$ & $2(12.5 \%)$ & $2(12.5 \%)$ & 0 & 0 & - \\
\hline
\end{tabular}

FU: FU time point $(\mathrm{T} 1=3 \mathrm{~m}, \mathrm{~T} 2=6 \mathrm{~m}$, and T3 $=12 \mathrm{~m})$; Norm: normal; Hyp: hypaesthesia; Par: paraesthesia; An: anaesthesia; MD: Missing Data. $P$ : the difference between the materials was not statistically significant.

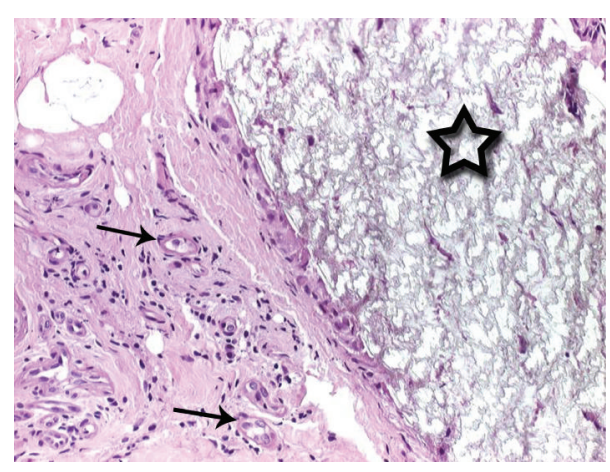

FIGURE 2: Histologic evaluation of a biodegradable material (asterix). Surrounding foreign body reaction with giant-cellformation (arrows).

and $\mathrm{H}_{2} \mathrm{O}$ via bulk hydrolysis; it is also metabolized by the liver (a two-phase degradation process) [40,41].

The resorption time of the metabolized components ranges between 6 and 18 months and can even occur up to 60 months [42, 43]. Generally, degradation characteristics depend on many factors of the material itself and the local tissue environment including the copolymer ratio, micro- and molecular structure, processing conditions, implant shape and thickness, and implantation site including vascularization. Initial biodegradable systems involved high-molecularweight polylactic acid polymers, but unfortunate foreign body reactions occurred and were attributed to their long resorption period $[44,45]$. BS, for example, is a copolymer formed by combining L-lactide and DL-lactide $(70: 30)$ to provide optimal strength and acceptable spatiotemporal degradation characteristics. It retains approximately $68 \%$ of its initial bending strength after 8 weeks, approximately $30 \%$ after 6 months, and has a total resorption time of 24 months [32]. The copolymer compositions and thus the degradation behavior of LS + DS differ slightly from that of BS. Despite their possible differences in stability during the fracture healing process and in the local tissue environment attributable to the different rates in the $\mathrm{pH}$ value decrease, only minor differences concerning the clinical outcome were apparent between BS, LS, and DS. BS exhibited slightly more long-term swelling and pain, as their overall degradation time span was longer than those of LS and DS. In the literature, some serious nonspecific foreign body reactions have been reported as being caused by high-molecular PLLA implants $[44,46,47]$. The PLLA remnants are surrounded by a fibrotic capsule and have been detected intracellularly. Even after 5.7 years, unabsorbed PLLA particles are present in the specimens $[44,46,47]$.

Another important aspect is the ability of the implantation site to dissolve and remove metabolized materials. Good vascularization leads to faster removal and prevents the accumulation of degradation products causing acidity of the tissue $[48,49]$.

After the first week of implantation, a rapid decline in strength of PLLA occurs, which might lead to premature failure [50]. A 50\% loss of strength by two weeks after implantation and a total loss of strength and consistency after 6 weeks limit the reliable clinical use of this material [50]. 
In an experimental study, four biodegradable materials (LactoSorb, Inion CPS 1.5 baby, Delta, and RFS) were evaluated, and their stability was tested in vitro via microrigidity [51]. LactoSorb and Inion CPS 1.5 baby were the weakest implants after three months. After a year, Delta and RFS were still rigid [51]. Biodegradable materials are composed of various combinations of poly ( $\alpha$-hydroxypolyesters), such as polylactic acid (PLA) and polyglycolic acid (PGA), and therefore show diverse intensities of inflammatory reaction because of their variable degradation rates $[30,52,53]$. Intraoperative warming of most OM (not BS) is needed in order to adapt the shape of the biodegradable material to the anatomical implantation site. Bergsma et al. speculate that this manipulation accelerates the degradation progress [49]. Furthermore, crystallinity leads to a slower absorption rate and is known to cause greater tissue reaction than with more easily absorbed components [48]. In future, polymethylmethacrylate bone cement bonding and degradable magnesium alloy implants [54, 55] might alternatively be used for the treatment of facial trauma, especially in the non-load-bearing region of the frontal and calvaria bone [56].

In our study, we have found a large number of complications such as pain, swelling, infections, and nerve disturbances. Most of the documented problems are related to the implantation site and not to the materials. However, we assume that the degradation process of the implants is another important reason for the high number of minor complications. Because of the inevitable drop of the local $\mathrm{pH}$-value, short- and long-term effects occur as the osmotic pressure is increased, so that the implant cavity is expanded or sterile fluid accumulates.

The shrinking of the periosteum, pain, and sensory disturbance, sometimes over many months, are probably the most important negative consequences for the patient. Buffering systems such as the incorporation of basic salts [57] and other modifications might reduce these unpleasant side effects and might therefore help to broaden the range of applications of these $\mathrm{OM}$ in the field of facial trauma and reconstruction and to increase patient acceptance. Many factors influence the physicochemical behavior and, consecutively, the degradation process of PLA [17]. Whereas low stress, high crystallinity, and orientation can reduce the degradation rate [58]; high temperature [59] and acidity [60] tend to induce the opposite.

However, further investigations with modified copolymer compositions, buffering systems, and biodegradable OM with more tissue-compatible physicochemical characteristics thus need to be carried out and analyzed.

In conclusion, the current study and the literature provide evidence that the use of biodegradable OM in the treatment of fractures of the midface and particularly in load-bearing applications such as the mandible is still not an alternative to the classic titanium OM and should therefore be reserved for specific indications. Moreover, long-term effects generated by the degradation process and its products have to be critically observed. Developments such as degradable magnesium alloy implants [54] might show stability comparable with titanium, might be an alternative to the latter, and might replace classic biodegradable OM.

\author{
Abbreviations

$\begin{array}{ll}\text { FU: } & \text { Follow-up } \\ \text { m: } & \text { Months } \\ \text { OM: } & \text { Osteosynthesis material } \\ \text { PLA: } & \text { Polylactic acid } \\ \text { PGA: } & \text { Polyglycolic acid } \\ \text { PDLA: } & \text { Poly-D-Lactic Acid } \\ \text { PLLA: } & \text { Poly-L-Lactic Acid } \\ \text { T: } & \text { Time point. }\end{array}$

\section{Conflict of Interests}

The authors declare that there is no conflict of interests regarding the publication of this paper.

\section{Authors' Contribution}

Andreas Kolk and Robert Köhnke contributed equally to this work.

\section{References}

[1] D. G. Bowers Jr. and J. B. Lynch, "Management of facial fractures," Southern Medical Journal, vol. 70, no. 8, pp. 910-918, 1977.

[2] R. Schmelzeisen, T. McIff, and B. Rahn, "Further development of titanium miniplate fixation for mandibular fractures. Experience gained and questions raised from a prospective clinical pilot study with $2.0 \mathrm{~mm}$ fixation plates," Journal of CranioMaxillofacial Surgery, vol. 20, no. 6, pp. 251-256, 1992.

[3] T. G. S. Fiala, R. A. Novelline, and M. J. Yaremchuk, "Comparison of CT imaging artifacts from craniomaxillofacial internal fixation devices," Plastic and Reconstructive Surgery, vol. 92, no. 7, pp. 1227-1232, 1993.

[4] E. Wiener, C. Pautke, T. M. Link, A. Neff, and A. Kolk, "Comparison of 16-slice MSCT and MRI in the assessment of squamous cell carcinoma of the oral cavity," European Journal of Radiology, vol. 58, no. 1, pp. 113-118, 2006.

[5] J. C. Yu, S. P. Bartlett, D. S. Goldberg et al., "An experimental study of the effects of craniofacial growth on the long-term positional stability of microfixation," The Journal of Craniofacial Surgery, vol. 7, no. 1, pp. 64-68, 1996.

[6] C. P. Case, V. G. Langkamer, C. James et al., "Widespread dissemination of metal debris from implants," The Journal of Bone \& Joint Surgery - British Volume, vol. 76, no. 5, pp. 701-712, 1994.

[7] E. N. Siniscalchi, L. Catalfamo, A. Allegra, C. Musolino, and F. S. De Ponte, "Titanium miniplates: a new risk factor for the development of the bisphosphonate-related osteonecrosis of the jaw," Journal of Craniofacial Surgery, vol. 24, no. 1, pp. e1-e2, 2013.

[8] A. U. Daniels, M. K. Chang, and K. P. Andriano, "Mechanical properties of biodegradable polymers and composites proposed for internal fixation of bone," Journal of Applied Biomaterials, vol. 1, no. 1, pp. 57-78, 1990.

[9] W. H. Harris, B. J. L. Moyen, E. L. Thrasher II et al., "Differential response to electrical stimulation: a distinction between induced osteogenesis in intact tibiae and the effect on fresh fracture defects in radii," Clinical Orthopaedics and Related Research, vol. 124, pp. 31-40, 1977. 
[10] R. K. Kulkarni, E. G. Moore, A. F. Hegyeli, and F. Leonard, "Biodegradable poly(lactic acid) polymers," Journal of Biomedical Materials Research, vol. 5, no. 3, pp. 169-181, 1971.

[11] L. K. Cheung, L. K. Chow, and W. K. Chiu, "A randomized controlled trial of resorbable versus titanium fixation for orthognathic surgery," Oral Surgery, Oral Medicine, Oral Pathology, Oral Radiology and Endodontology, vol. 98, no. 4, pp. 386-397, 2004.

[12] R. K. Kulkarni, K. C. Pani, C. Neuman, and F. Leonard, "Polylactic acid for surgical implants," Archives of Surgery, vol. 93, no. 5, pp. 839-843, 1966.

[13] K. L. Gerlach, "Resorbable polymers as osteosynthesis material," Mund Kiefer Gesichtschir, vol. 4, supplement 1, pp. S91-S102, 2000.

[14] K. L. Gerlach, "In-vivo and clinical evaluations of poly(Llactide) plates and screws for use in maxillofacial traumatology," Clinical Materials, vol. 13, no. 1-4, pp. 21-28, 1993.

[15] S. J. Gourlay, R. M. Rice, A. F. Hegyeli et al., "Biocompatibility testing of polymers: in vivo implantation studies," Journal of Biomedical Materials Research, vol. 12, no. 2, pp. 219-232, 1978.

[16] A. Kolk, C. Haczek, C. Koch et al., "A strategy to establish a gene-activated matrix on titanium using gene vectors protected in a polylactide coating," Biomaterials, vol. 32 , no. 28 , pp. $6850-$ 6859, 2011.

[17] A. Kolk, J. Handschel, W. Drescher et al., "Current trends and future perspectives of bone substitute materials-from space holders to innovative biomaterials," Journal of CranioMaxillofacial Surgery, vol. 40, no. 8, pp. 706-718, 2012.

[18] J. Vasenius, S. Vainionpää, K. Vihtonen et al., "Comparison of in vitro hydrolysis, subcutaneous and intramedullary implantation to evaluate the strength retention of absorbable osteosynthesis implants," Biomaterials, vol. 11, no. 7, pp. 501-504, 1990.

[19] J. A. Goldstein, F. A. Quereshy, and A. R. Cohen, "Early experience with biodegradable fixation for congenital pediatric craniofacial surgery," Journal of Craniofacial Surgery, vol. 8, no. 2, pp. 110-115, 1997.

[20] K. D. Kiely, K. S. Wendfeldt, B. E. Johnson, B. S. Haskell, and R. C. Edwards, "One-year postoperative stability of LeFort I osteotomies with biodegradable fixation: a retrospective analysis of skeletal relapse," American Journal of Orthodontics and Dentofacial Orthopedics, vol. 130, no. 3, pp. 310-316, 2006.

[21] G. Wittwer, W. L. Adeyemo, M. Voracek et al., "An evaluation of the clinical application of three different biodegradable osteosynthesis materials for the fixation of zygomatic fractures," Oral Surgery, Oral Medicine, Oral Pathology, Oral Radiology and Endodontology, vol. 100, no. 6, pp. 656-660, 2005.

[22] G. Wittwer, W. L. Adeyemo, K. Yerit et al., "Complications after zygoma fracture fixation: Is there a difference between biodegradable materials and how do they compare with titanium osteosynthesis?" Oral Surgery, Oral Medicine, Oral Pathology, Oral Radiology and Endodontology, vol. 101, no. 4, pp. 419425, 2006.

[23] B. L. Eppley, C. D. Prevel, A. M. Sadove, and D. Sarver, "Resorbable bone fixation: its potential role in craniomaxillofacial trauma," Journal of Cranio-Maxillofacial Trauma, vol. 2, no. 1, pp. 56-60, 1996.

[24] G. Enislidis, G. Lagogiannis, G. Wittwer, C. Glaser, and R. Ewers, "Fixation of zygomatic fractures with a biodegradable copolymer osteosynthesis system: short- and long-term results," International Journal of Oral \& Maxillofacial Surgery, vol. 34, no. 1, pp. 19-26, 2005.
[25] L. Yang, M. Xu, X. Jin et al., "Complications of absorbable fixation in maxillofacial surgery: a meta-analysis," PLOS ONE, vol. 8, no. 6, Article ID e67449, 2013.

[26] D. E. Cutright, E. E. Hunsuck, and J. D. Beasley, "Fracture reduction using a biodegradable material, polylactic acid," Journal of Oral Surgery, vol. 29, no. 6, pp. 393-397, 1971.

[27] B. L. Schmidt, D. H. Perrott, D. Mahan, and G. Kearns, "The removal of plates and screws after Le Fort I osteotomy," Journal of Oral and Maxillofacial Surgery, vol. 56, no. 2, pp. 184-188, 1998.

[28] B. R. Simon, S. L.-Y. Woo, M. McCarty, S. Lee, and W. H. Akeson, "Parametric study of bone remodeling beneath internal fixation plates of varying stiffness," Journal of Bioengineering, vol. 2, no. 6, pp. 543-556, 1978.

[29] J. S. Orringer, V. Barcelona, and S. R. Buchman, "Reasons for removal of rigid internal fixation devices in craniofacial surgery," Journal of Craniofacial Surgery, vol. 9, no. 1, pp. 40-44, 1998.

[30] P. Schumann, D. Lindhorst, M. E. H. Wagner, A. Schramm, N.-C. Gellrich, and M. Rücker, "Perspectives on resorbable osteosynthesis materials in craniomaxillofacial surgery," Pathobiology, vol. 80, no. 4, pp. 211-217, 2013.

[31] B. L. Eppley and A. M. Sadove, "Effects of resorbable fixation on craniofacial skeletal growth: a pilot experimental study," The Journal of Craniofacial Surgery, vol. 3, no. 4, pp. 190-196, 1992.

[32] R. B. Bell and C. S. Kindsfater, "The use of biodegradable plates and screws to stabilize facial fractures," Journal of Oral and Maxillofacial Surgery, vol. 64, no. 1, pp. 31-39, 2006.

[33] P. U. Rokkanen, "Absorbable materials in orthopaedic surgery," Annals of Medicine, vol. 23, no. 2, pp. 109-115, 1991.

[34] A. A. Ignatius and L. E. Claes, "In vitro biocompatibility of bioresorbable polymers: poly(L, DL-lactide) and poly(Llactide-co-glycolide)," Biomaterials, vol. 17, no. 8, pp. 831-839, 1996.

[35] B. Saad, G. Ciardelli, S. Matter et al., "Characterization of the cell response of cultured macrophages and fibroblasts to particles of short-chain poly[(R)-3-hydroxybutyric acid]," Journal of Biomedical Materials Research, vol. 30, no. 4, pp. 429-439, 1996.

[36] M. C. Wake, P. D. Gerecht, L. Lu, and A. G. Mikos, "Effects of biodegradable polymer particles on rat marrow-derived stromal osteoblasts in vitro," Biomaterials, vol. 19, no. 14, pp. 1255-1268, 1998.

[37] H. Pihlajamäki, J. Kinnunen, and O. Böstman, "In vivo monitoring of the degradation process of bioresorbable polymeric implants using magnetic resonance imaging," Biomaterials, vol. 18, no. 19, pp. 1311-1315, 1997.

[38] R. A. Miller, J. M. Brady, and D. E. Cutright, "Degradation rates of oral resorbable implants (polylactates and polyglycolates): rate modification with changes in PLA/PGA copolymer ratios," Journal of Biomedical Materials Research, vol. 11, no. 5, pp. 711719, 1977.

[39] D. E. Cutright, B. Perez, J. D. Beasley III, W. J. Larson, and W. R. Posey, "Degradation rates of polymers and copolymers of polylactic and polyglycolic acids," Oral Surgery, Oral Medicine, Oral Pathology, vol. 37, no. 1, pp. 142-152, 1974.

[40] W. S. Pietrzak, "Principles of development and use of absorbable internal fixation," Tissue Engineering, vol. 6, no. 4, pp. 425-433, 2000.

[41] W. S. Pietrzak, D. R. Sarver, and M. L. Verstynen, "Bioabsorbable polymer science for the practicing surgeon," Journal of Craniofacial Surgery, vol. 8, no. 2, pp. 87-91, 1997. 
[42] M. J. Imola, D. D. Hamlar, W. Shao, K. Chowdhury, and S. Tatum, "Resorbable plate fixation in pediatric craniofacial surgery: long-term outcome," Archives of Facial Plastic Surgery, vol. 3, no. 2, pp. 79-90, 2001.

[43] J. Wiltfang, H.-A. Merten, S. Schultze-Mosgau, U. Schrell, D. Wénzel, and P. Keßler, "Biodegradable miniplates (LactoSorb): long-term results in infant minipigs and clinical results," Journal of Craniofacial Surgery, vol. 11, no. 3, pp. 239-243, 2000.

[44] E. J. Bergsma, F. R. Rozema, R. R. M. Bos, and W. C. de Bruijn, "Foreign body reactions to resorbable poly(L-lactide) bone plates and screws used for the fixation of unstable zygomatic fractures," Journal of Oral and Maxillofacial Surgery, vol. 51, no. 6, pp. 666-670, 1993.

[45] R. R. M. Bos, G. Boering, F. R. Rozema, and J. W. Leenslag, "Resorbable poly(L-lactide) plates and screws for the fixation of zygomatic fractures," Journal of Oral and Maxillofacial Surgery, vol. 45, no. 9, pp. 751-753, 1987.

[46] J. E. Bergsma, W. C. de Bruijn, F. R. Rozema, R. R. M. Bos, and G. Boering, "Late degradation tissue response to poly(L-lactide) bone plates and screws," Biomaterials, vol. 16, no. 1, pp. 25-31, 1995.

[47] R. R. M. Bos, F. B. Rozema, G. Boering et al., "Degradation of and tissue reaction to biodegradable poly(L-lactide) for use as internal fixation of fractures: a study in rats," Biomaterials, vol. 12, no. 1, pp. 32-36, 1991.

[48] P. Laine, R. Kontio, C. Lindqvist, and R. Suuronen, "Are there any complications with bioabsorbable fixation devices? A 10 year review in orthognathic surgery," International Journal of Oral and Maxillofacial Surgery, vol. 33, no. 3, pp. 240-244, 2004.

[49] J. E. Bergsma, F. R. Rozema, R. R. M. Bos, G. Boering, W. C. de Bruijn, and A. J. Pennings, "In vivo degradation and biocompatibility study of in vitro pre-degraded as-polymerized polylactide particles," Biomaterials, vol. 16, no. 4, pp. 267-274, 1995.

[50] P. Tormala, J. Vasenius, S. Vainionpaa, J. Laiho, T. Pohjonen, and P. Rokkanen, "Ultra-high-strength absorbable self-reinforced polyglycolide (SR-PGA) composite rods for internal fixation of bone fractures: in vitro and in vivo study," Journal of Biomedical Materials Research, vol. 25, no. 1, pp. 1-22, 1991.

[51] J. Düchting, Chemische und mechanische Eigenschaften bioresorbierbarer Osteosyntheseplatten nach in-vitro Degradation [M.S. thesis], Department of Maxillofacial and Facial Plastic Surgery, University of Rostock, Rostock, Germany, 2008.

[52] J. C. Posnick and R. L. Ruiz, "Treacher Collins syndrome: current evaluation, treatment, and future directions," Cleft Palate-Craniofacial Journal, vol. 37, no. 5, p. 434, 2000.

[53] J. C. Posnick and R. L. Ruiz, "The craniofacial dysostosis syndromes: current surgical thinking and future directions," Cleft Palate-Craniofacial Journal, vol. 37, no. 5, p. 433, 2000.

[54] Y. Li, C. Wen, D. Mushahary et al., "Mg-Zr-Sr alloys as biodegradable implant materials," Acta Biomaterialia, vol. 8, no. 8, pp. 3177-3188, 2012.

[55] R. Smeets, K. Endres, G. Stockbrink et al., "The innovative application of a novel bone adhesive for facial fracture osteosynthesis -in vitro and in vivo results," Journal of Biomedical Materials Research A, vol. 101, no. 7, pp. 2058-2066, 2013.

[56] C. A. Landes and A. Ballon, "Indications and limitations in resorbable $\mathrm{P}(\mathrm{L} 70 / 30 \mathrm{DL}) \mathrm{LA}$ osteosyntheses of displaced mandibular fractures in 4.5-year follow-up," Plastic and Reconstructive Surgery, vol. 117, no. 2, pp. 577-587, 2006.
[57] C. M. Agrawal and K. A. Athanasiou, "Technique to control $\mathrm{pH}$ in vicinity of biodegrading PLA-PGA implants," Journal of Biomedical Materials Research, vol. 38, no. 2, pp. 105-114, 1997.

[58] R. M. Felfel, I. Ahmed, A. J. Parsons, P. Haque, G. S. Walker, and C. D. Rudd, "Investigation of crystallinity, molecular weight change, and mechanical properties of PLA/PBG bioresorbable composites as bone fracture fixation plates," Journal of Biomaterials Applications, vol. 26, no. 7, pp. 765-789, 2012.

[59] N. A. Weir, F. J. Buchanan, J. F. Orr, D. F. Farrar, and G. R. Dickson, "Degradation of poly-L-lactide. Part 2: increased temperature accelerated degradation," Proceedings of the Institution of Mechanical Engineers, Part H: Journal of Engineering in Medicine, vol. 218, no. 5, pp. 321-330, 2004.

[60] Y. Shikinami and M. Okuno, "Bioresorbable devices made of forged composites of hydroxyapatite (HA) particles and poly-Llactide (PLLA): part I. Basic characteristics," Biomaterials, vol. 20, no. 9, pp. 859-877, 1999. 


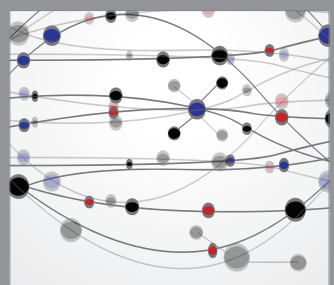

The Scientific World Journal
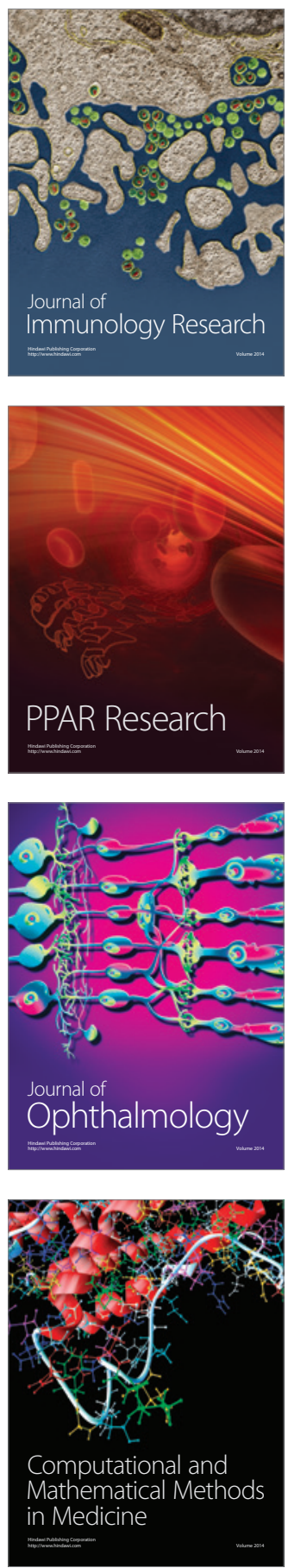

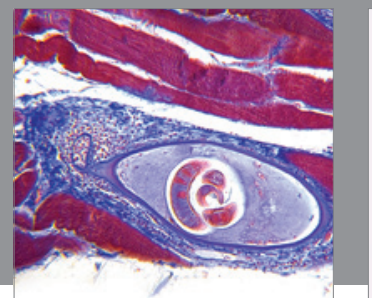

Gastroenterology

Research and Practice
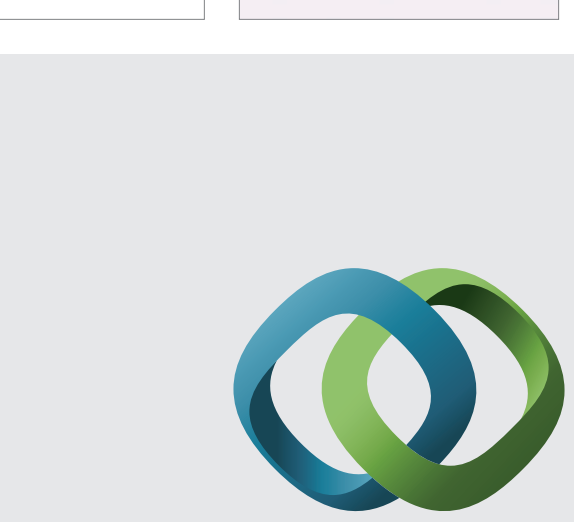

\section{Hindawi}

Submit your manuscripts at

http://www.hindawi.com
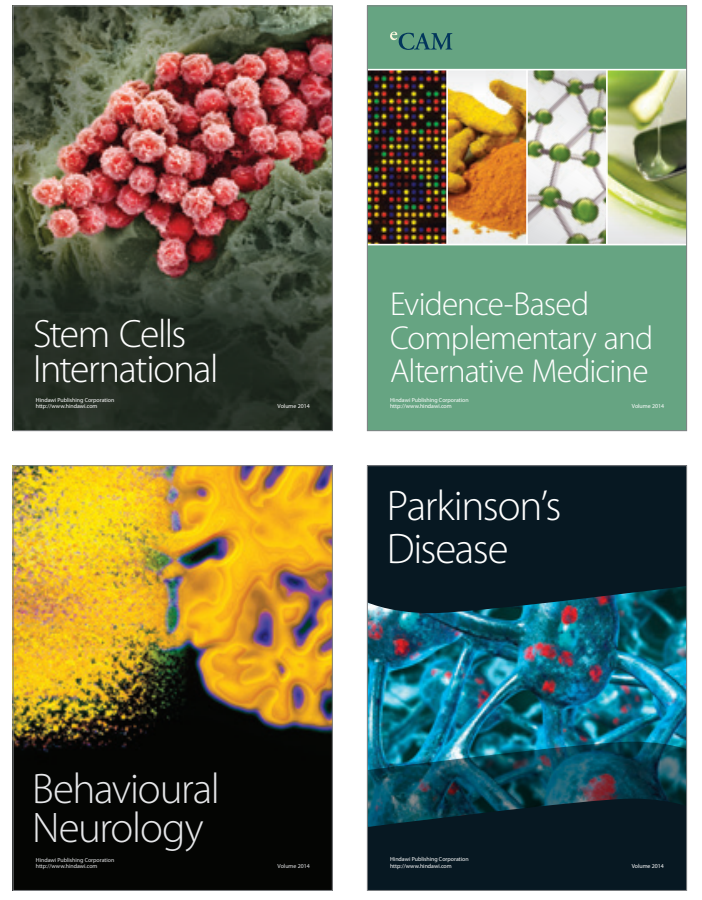
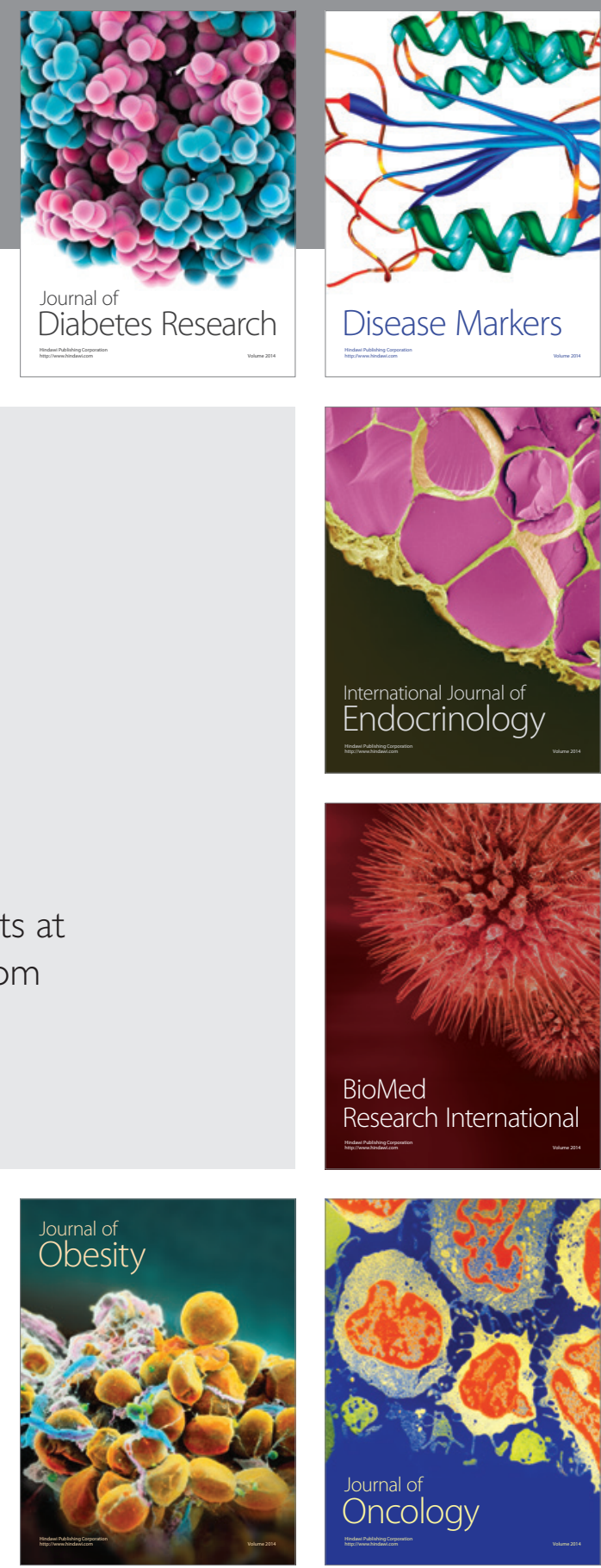

Disease Markers
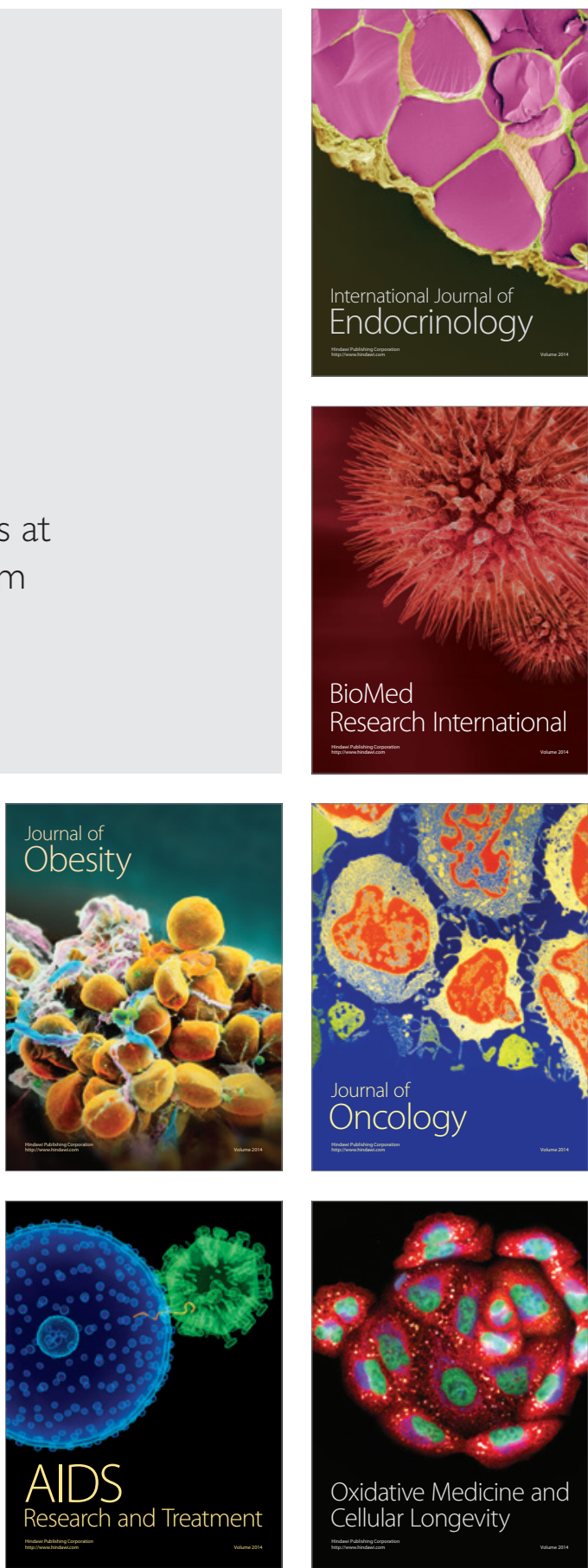